\title{
Trash or treasure, where is the line? Issues, limitations and opportunities for reusing and recycling waste: a South Australian perspective
}

\author{
A. W. Lewis \& M. Wagner \\ Waste to Resources Branch, Environment Protection Authority, \\ South Australia
}

\begin{abstract}
The Environment Protection Act 1993 of South Australia (the Act) was proclaimed in 1995 and is the primary environmental regulatory tool to control the potential adverse environmental impacts generated from industrial activities in the state, including the waste industry. In recent times, regulation has not kept pace with rapid changes in waste management in the more non-traditional waste reuse and recycling areas. In particular, the development of alternative resource recovery initiatives is rapidly increasing, including alternative fuels and proposed reuse by application of wastes including industrial residues to land. These issues have generally been addressed by the Environment Protection Authority in South Australia (EPA) on a case-by-case basis through a process of demonstration and assessment of the risks and suitability of individual proposals. Although the process was sound in each case, there was no officially published position or guidelines through which the broader industry has been advised by the EPA of the expectations and requirements incumbent upon them in order to undertake such activities. As part of the resolution of this matter, a programme was commenced in 2007 to address the issues and options for improving waste management practices and the regulatory system that controls these emerging activities in South Australia. This paper will discuss these issues, the inherent limitations and the manner in which the identified gaps are being addressed, with the difficult task of bringing the often conflicting expectations and viewpoints of the regulator, the public and the industry together.
\end{abstract}

Keywords: regulation, waste, recycling, reuse, South Australia. 


\section{Introduction}

The environmental obligations in the more traditional areas of managing waste including disposal of waste to landfill as well as recycling including plastics, glass, metal, organic waste, paper and cardboard and inert construction and demolition waste are relatively well established, managed and understood. However significant changes to waste management in South Australia have occurred including the rationalisation of landfills, improved consistency and standards for landfills and an increase in the government levy on disposal of waste. This along with innovation and development of alternative waste technologies and waste derived products has led to a situation whereby there is a gap between the industry processes and government policy and technical guidance in South Australia.

This has highlighted the need for the regulator to undertake a comprehensive programme to ensure that these initiatives develop in a beneficial, scientifically sound and environmentally responsible manner and that there is a comprehensive, functional and well understood regulatory system that supports it. In particular, the processes and product quality for refuse derived fuel, the beneficial application of waste to land and the use of waste as fill are key issues to address and were specifically noted in a report by a Subcommittee of the Board of the EPA [1].

\subsection{Brief facts for $\mathrm{SA}$}

Tailored solutions are required for waste management in South Australia due to its large area, relatively small population and small total waste volumes. The state has an estimated population of $1,542,000$, of which approximately $75 \%$ is situated in its capital Adelaide, with the remainder spread over its total land area of $985,334 \mathrm{~km} 2$. It has a mainly Mediterranean climate with a semi-arid to arid climate towards central Australia. The average annual rainfall in the south east of South Australia ranges from approximately $400-600 \mathrm{~mm}$ and $0-300 \mathrm{~mm}$ for the remainder of the state, with the average annual daily maximum temperatures ranging from around 15 to $33^{\circ} \mathrm{C}$ [2].

South Australians generated an estimated 3,447,269 tonnes of waste in $2005 / 2006$, with a reported diversion rate across the Municipal, Commercial and Industrial and Construction and Demolition waste streams of $69.5 \%$ [3].

Recycling of traditional waste materials is well developed in South Australia; the state has had Container Deposit Legislation since 1975, whereby there is a refund on certain recyclable containers. This has resulted in generally high diversion rates of these wastes and will be doubled to $\$ 0.10$ during 2008. In addition, most metropolitan areas have kerbside waste collection schemes that include 3-bin systems to separate household putrescible waste from dry recyclables and green waste. The main areas where improved recycling rates could be achieved are the commercial and industrial, and construction and demolitions sectors. However bona fide processes and product quality are key issues that need to be addressed. 


\section{Legislative and administrative tools}

There are a variety of tools that can be used to regulate industry. South Australia uses a variety of legislative and administrative approaches to achieve the objects of the Act, which include, to promote principles of ecologically sustainable development and to ensure that all reasonable and practicable measures are taken to protect, restore and enhance the quality of the environment.

\subsection{The Act}

The South Australia Environment Protection Act 1993 (the Act) defines 'scheduled activities of environmental significance' that require an environmental authorisation to operate, including 'waste or recycling depots'. The Act defines waste as,

“(a) any discarded, rejected, abandoned, unwanted or surplus matter, whether or not intended for sale or for recycling, reprocessing, recovery or purification by a separate operation from that which produced the matter; or

(b) anything declared by regulation (after consultation under section 5A) or by an environment protection policy to be waste, whether of value or not." [4]

Furthermore, there is an obligation under the Act called the "General Environmental Duty' that applies to all South Australians, which states that " $A$ person must not undertake an activity that pollutes, or might pollute, the environment unless the person takes all reasonable and practicable measures to prevent or minimise any resulting environmental harm" [4].

\subsection{The policy}

South Australia also has an Environment Protection Policy for waste, however it is limited in its application. As such, a new Environment Protection (Waste to Resources) Policy is currently under development. The regulatory tools in place under the Act are mainly tools to require compliance but can be generally categorised as end of pipe solutions. There is little or no legislation that addresses sustainability in waste management or to set out any such obligations for generators and industry. It is anticipated that the new Policy will assist in addressing some of these issues.

\subsection{The levy}

The disposal of waste to authorised landfill incurs a government levy, which was doubled in July 2007 to AU\$11.70 per tonne of waste disposed for regional areas and $\$ 23.40$ per tonne in metropolitan areas. Although intended as an incentive to divert waste for recycling rather than disposal, the levy is charged at disposal facilities and not at the gate of recycling facilities. This has caused some concern that either there would be an increase in illegal dumping and/or increased 
diversion to inappropriate recycling or reuses. Other schools of thought question whether the dollar value of the levy is sufficiently high to be the incentive it is intended to be. Although it is early days in its implementation, there is some suggestion that volumes of waste to landfill have been reduced. The key question is then, to what beneficial reuse has this waste been diverted?

\subsection{The guidelines}

The EPA has published detailed environmental guidelines and standards for example for landfill facilities and a separate guideline for recycling and transfer facilities. The aim was to produce guidelines that would be the most appropriate and best practice for South Australia, not necessarily world's best practice. The landfill guidelines drew from international experience and expertise including from Canada, and from South Africa in particular as it had similar climatic and geographic issues to contend with. Collaboration with international expertise as well local consultation has produced guidelines that have risk based standards as well as the flexibility to allow proposals to demonstrate equivalency. The EPA has been actively working with waste and recycling depot operators (landfills and transfer stations in particular) to ensure their design, operation and closure occurs in an environmentally acceptable manner.

Some guidance also exists in relation to reuse of wastewater and biosolids, and industry has some recycled concrete and asphalt product quality standards. There is additional national guidance for the reuse of industrial residues to land for beneficial agricultural reuse. However there are minimal state based waste reuse quality and regulatory standards in place, particularly for solid wastes.

\subsection{The rationalisation of landfills}

Through a statutory body called Zero Waste SA, the government, has been promoting rationalisation of landfills. The EPA being the key environmental regulator in the state supports this approach where it is feasible to combine resources to operate fewer and better designed facilities for the protection of the environment and to encourage recycling and diversion of waste to appropriate reuses.

However, in addition to the economic instrument of the levy, programmes for landfill rationalisation and implementation of appropriate standards often come at an unavoidable cost. This is particularly the case where local councils have existing facilities that are substandard and may not be operated in a manner that fully recovers costs, and which may also have long distances to transport waste to more suitable alternative sites. The EPA and the industry inclusive of local government are continuing to seek suitable and practical solutions to these difficulties.

\subsection{Other mechanisms}

There are other mechanisms that can be seen as part of overall improved sustainability in waste management; however these are not specifically part of the waste reform project discussed here. Such mechanisms include the National 
Packaging Covenant and a supporting National Environment Protection Measure for used packaging material, which is being implemented in South Australia through the Environment Protection (Used Packaging Materials) Policy 2001. There are also various programmes to educate businesses in cleaner production and reducing their ecological footprint, to provide grants to assist in the provision of recycling infrastructure and to collect and safely treat or dispose of hazardous waste and chemical containers from the general community.

\section{The challenge}

Although it would appear relatively clear what jurisdiction the EPA has in relation to the regulation of waste processing and disposal activities, an issue arises where a person deems that they have processed a waste to the point that it is no longer a waste but a product.

With the aim of sustainable integrated waste and resource management to maximise value and prevent or minimise adverse impact, there is a need to ensure that it is in fact recycling, not 'downcycling' that is occurring. A key aspect of this is to ensure that acceptable wastes are being processed using suitable technologies in order to demonstrate that the appropriate standards for reuse are being achieved. The EPA will need to ensure that the policy and guidelines developed will provide greater clarity and will meet and complement the various technologies available whilst remaining sufficiently flexible to deal with newly emerging technologies and in determining appropriate solutions to this challenge the EPA will again look to the experiences of other jurisdictions.

This issue is not unique to South Australia, as many other places in the world are looking at what are acceptable processes and standards for recycling and reuse of waste and hence what supporting regulatory framework is required: as they say, 'one man's trash is another man's treasure'. However this issue becomes important when there are potential risks to the environment from either the stockpiling or storage of these materials or their use in the environment for example in filling of land, as well as risks to the regulatory environment. The conflicting viewpoints presented in this cliché highlight the area where much concern is caused and thus the challenge for the regulator to develop a system that will address and balance the expectations of industry, the community and the regulator, whilst ensuring protection of its charge, the environment.

\section{The way forward}

The question over 'what is waste' is often a source of much debate. In order to resolve this matter however, it is viewed that the need lies in determining appropriate technical standards and processes for recycling and reuse of wastes, rather than focus on the definitions and semantics involved. In addition, there is a real need to develop robust administrative processes through which proponents must proceed in order to demonstrate the suitability for use. The processing and production of waste derived products should therefore be based on key guiding principles for waste management. 


\subsection{Guiding principles for the regulation of waste to resources}

The guiding principles for the management of waste to resources in South Australia were developed in order to provide a concise but overarching framework that will guide the approach that the regulator will have to the waste to resources industry. These Principles are as follows:

PRINCIPLE 1 - The EPA will support and encourage the use of the Waste Hierarchy including to manage waste at the point of generation, to avoid, reduce and segregate rather than dilute in order to ensure the highest, best, available and safe reuse of waste and waste by-products whilst ensuring safe disposal of residual wastes.

PRINCIPLE 2 - The EPA will uphold a Risk Based Approach to regulation using sound science and where appropriate, a precautionary approach in the application of regulatory tools, standards and decisions to minimise the potential risk of environmental harm.

PRINCIPLE 3 - The EPA will seek to maximise Resource Efficiency and will require appropriate Quality Assurance and Quality Controls to ensure recycling is conducted to specified standards and to demonstrate the reuse is genuine, beneficial and fit for purpose. A waste derived product should have an immediate market to avoid speculative accumulation of waste. The process should use available and feasible technologies to produce a recycled product that replaces a raw material with no greater risk of causing potential harm.

PRINCIPLE 4 - The EPA will ensure a Consistent Approach to regulation is implemented to achieve acceptable outcomes by continued development of the regulatory framework, guidelines and standards. Regulation must be effective, transparent and flexible with consideration to a changing environment and market while maintaining the integrity of the regulatory system. The responsibility for waste starts with the waste generator and waste processors and therefore the system needs to reflect the Polluter Pays principle. [5].

These Principles are in line with but expand upon, the Objects in relation to waste as set out in Section 10 of the Act.

\subsection{Options and limitations}

With a need to focus on the recycling and reuse processes, the issues that need to be considered in relation to strong quality assurance and controls are: What is the nature of the waste; which process is suitable for that waste; what products and residual wastes can be expected from the process; and hence, what is the suitable fate for those process outputs?

The following section describes some examples of waste processing technologies to highlight the issues in this regard.

\subsubsection{Waste processing technologies}

The following is a brief outline of some of the waste processing technologies that are available.

The segregation and processing of dry commingled recyclable wastes such as glass, plastics, metals, paper and cardboard is one of the more established and 
well controlled waste recycling systems. Each of these items can be reprocessed back into recycled products. The technology used to do this segregation is generally referred to as a Materials Recovery Facility (MRF) as it recovers the collected recyclable wastes for subsequent processing back into recognised and to specification recycled products, which remain within the wider economy. The process is most suited to these dry recyclable wastes rather than general mixed waste. Where the input is unsorted Municipal Solid Waste (MSW), the process requires additional components and is normally referred to as a dirty MRF. It is more difficult as the recyclables are more likely to be contaminated with other waste. In addition to dirty MRFs that process unsorted MSW, more involved technology is also required for processing other mixed wastes such as that from commercial and industrial premises.

These additional technologies include Mechanical Biological Treatment (MBT), which can incorporate a variety of technologies such as sieving, sinkfloat tanks and anaerobic biological digestion (AD) to pre-treat and stabilise the waste for disposal. Alternatively, some stabilised waste may be able to be used as feedstock to further waste treatment or disposal processes. These include directing the waste to incineration and subsequent capture of the energy (EfW), for production or use as refuse derived fuel (RDF) in an industrial process such as a kiln, or for energy recovery in a gasification / co-incineration style EfW plant. Some wastes can also be digested into a fertiliser type of product using AD or in vessel composting with capture and use of biogas [6].

\subsubsection{Need for quality assurance and controls in South Australia's waste industry}

South Australia does not have any dirty MRFs or true MBTs. However it has MRFs for dry recyclables and also facilities that process other mixed dry waste from commercial and industrial premises and mixed waste from construction and demolition sites. The term MRF is generally used to describe both types of processes in South Australia. These mixed waste MRFs use a mechanical treatment process to recover bulk recyclables such as metals. One facility also produces a fuel for a cement kiln, following a trial that derived a suitable RDF from $90 \%$ timber and 10\% plastics.

In the European Union (EU), the landfill and incineration directives have driven the development of MBT technologies, but with a focus on not only diverting waste, but also the pre-treatment of wastes to transform them into less harmful partially stabilised wastes for safer disposal to landfill. Particularly in relation to the mixed waste MRFs in South Australia, there is naturally a residual waste component that is unsuitable for processing into recycled or waste derived products or refuse derived fuel. Some of the challenges being faced stem from these residual waste streams and their management, as alternative uses are being sought rather than safe disposal to authorised landfill.

\subsection{The development of guidance for industry - processes and key elements}

Recycling of materials so that they remain within the wider economy or disposing of residual wastes to authorised landfill does not present the greatest 
concern for waste management in South Australia at present. A current concern is however the example of proposed alternative reuse such as by application to land of residual wastes that may be of unknown or inconsistent quality.

The guidance under development currently is to address the application of sufficient QA/QC to address risk and to demonstrate the suitably of the processed waste for beneficial reuse as fill, or to land as soil conditioners or fertiliser (inclusive of liquid wastes), and the production of refuse derived fuel. It has been identified that this guidance needs to be developed in a broad enough manner so that the principles for reuse and the processes that proponents must go through to gain approval, should also encompass existing and emerging issues. It should also be noted that provided well designed and located landfill facilities are available, these remain a viable destination for residual wastes for which there is no suitable reuse option at this point in time in South Australia.

The focus on the development of guidance documentation will include requirements to demonstrate the:

- Avoidance of harm to the environment and human health;

- Beneficial component of the proposed reuse; and

- Fit for purpose standards of their products.

Some guidance may draw on product standards that may already exist, such as Australian Standards for compost. Other guidance may only set out the process for demonstration of suitability based on a risk and precaution approach.

Some key elements that are intended to be included in the guidance are:

- Ensuring the best and safe reuse, recycling or disposal of wastes

- Describing where possible, suitable waste processing technologies

- Requiring suitable quality controls to manage the process inputs

- Requiring segregation of recyclable wastes at processing facilities

- Requiring quality assurance for process outputs

- Requiring demonstration of suitability for use of waste derived products

- Prohibiting some types of wastes from application to land

- Specifying criteria, threshold limits and efficiency targets where possible

\subsubsection{Engagement and consultation and further work}

The undertaking of this waste reform project has the aim to ensure all parties understand and accept the final outcomes. It is hoped that this aim will be achieved through consultative engagement with industry. Although there is a risk that all parties may not agree with all final outcomes, it is anticipated that a better final outcome will be achieved through the use of this valuable and important engagement process in the development of guidance documents.

The project is in its early stages and the guidance documents will be drafted during 2008. There are likely to be areas of waste management that require better clarity and guidance but which are unable to fit within the scope or timeframes of this particular project; these will be noted as further work required. It is also recognised that a continual review and improvement process will be required as further learning occurs. In a changing environment and an ever dynamic waste industry, the challenges, innovations and needs for new approaches are unlikely to wane and therefore the work of the regulator to review and improve environmental outcomes will need to continue. 


\section{Conclusion}

For all waste management processes it is clear that there needs to be robust quality controls applied. The inputs need to be specific and clearly defined in relation to the process. The problematic and residual materials need to be removed and treated or disposed in a responsible manner and the process for recycling and reuse as fill, for beneficial land application, or as refuse derived fuel needs to include clearly demonstrable benefits and avoidance of harm to the environment and be based on sound science. The waste reform project to review waste management, reuse and recycling activities in South Australia will provide better clarity of expectations and standards required for all parties.

The EPA is aware of often conflicting expectations between the regulator, community and industry; however by taking a consultative approach, the final outcomes are anticipated to be more widely accepted. The challenge for the EPA as the regulator is to bring all these competing expectations together in a functioning and sustainable regulatory system that protects the environment and human health and ensures industry develops in a sustainable manner.

\section{References}

[1] EPA Board Waste to Resources Subcommittee Report, October 2007, Online www.epa.sa.gov.au/pdfs/CommitteeReport.pdf

[2] Australian Bureau of Statistics, Web Site www.abs.gov.au accessed January 2008

[3] ZWSA, Recycling Activity in South Australia 2005-06, 2007 Online http://www.zerowaste.sa.gov.au/pdf/reports/recycling_activity_2005-06.pdf

[4] Environment Protection Act 1993 (South Australia) Online, www.legislation.sa.gov.au/listActs.aspx?key=E

[5] Environment Protection Authority (South Australia), Guiding Principles for the Regulation of Waste to Resources Activities February 2008, unpublished draft.

[6] Enviros Consulting Ltd, Waste Technology - Mechanical Biological Treatment Web site www.waste-technology.co.uk/index.html, accessed January 2008 